\title{
Structural Analysis of Front-End Cross Bar of a TATA407 Chassis Frame
}

\author{
A. Benjamin Asirdason and B. Stalin
}

\begin{abstract}
The automotive industries are advancing various systems of a vehicle with innovative technologies. It is more essential to improve the vehicle performance at low manufacturing cost. Reduction of weight of various parts of a vehicle can improve the performance and efficiency of the automobile. The composite materials provide a good strengthto-weight ratio, which could be replaced for the conventional materials. This paper deals with the structural analysis of a frontend cross bar which is replaced with Carbon Fiber Reinforced Polymer composite material. The front-end cross bar of a TATA407 vehicle frame is modelled using the CREO 2.0 modelling software and analysed through Ansys Workbench 14.5. the stress distribution and deflection results of the convetional steel and CFRP cross bars were compared. The strength-to-weight ratio has improved when CFRP is used.
\end{abstract}

Keywords--- Performance, Efficiency, Conventional, CFRP, TATA 407, Cross Bar, CREO, Ansys, Stres, Deflection.

\section{INTRODUCTION}

$\mathrm{T}$ HE chassis is the basic frame that supports the major components of the vehicle. The chassis frame is mounted with the Transmission system, Axles, Wheels and Tyres, Suspension etc. The reduction of the weight of vehicle frame improves the vehicle performance in many aspects. The carbon fibers are lower in cost wise than steel and much stronger. Hence, CFRP are more suitable and widely used alternate material for automotive.

In this paper the chassis type of TATA 407 is considered, which is of ladder type with diagonal cross member. The frame consists of two longitudinal members of C-cross section, two diagonal cross members of C-cross section in the middle, two transverse cross members of C-cross section at the rear end and one transverse cross member of box-cross section at the front end. The chassis was modelled in CREO using most of the actual dimensions. Finite element analysis was done usng ANSYS 14.5.

\section{LITERATURE SURVEY}

C.V. Babu et al. (2015) [1] have analysed the Eicher 11.10 chassis frame. The conventional steel frame is entirely replaced with CFRP to obtain better strength-to-weight ratio.

A. Benjamin Asirdason, PG Scholar, Department of Mechanical Engineering, Anna University, Regional Campus, Madurai, Tamilnadu, India. E-mail:basirdason@gmail.com

B. Stalin, Assistant Professor, Department of Mechanical Engineering, Anna University, Regional Campus, Madurai, Tamilnadu, India. E-mail:stalin1312@gmail.com DOI:10.9756/BIJIEMS.7540
The stress and deflection results are better in composite frame than the conventional steel frame.

Ms. Kshitija et al. (2014) [2] have conducted a failure analysis on the Tractor Trolley chassis using the Finite Element Method. The results have shown that the stresses get accumulated at a region where heavy loads are applied, which is also indirectly related to the self-weight of the frame. Thus it is required to redesign the chassis with respect to the stress strain analysis and thereby reducing the self-weight of the trolley.

H.B. Patil et al. (2013) [3] have analysed the stress of a ladder type low loader truck chassis structure. The objective of the work was to reduce the cost of the chassis frame by reducing the thickness of the side member and cross member, and changing the position of the cross member. It was concluded that, changing the thickness of the cross member gave better reduction in stress and deflection values than changing the thickness of cross member and the position of cross member.

J.S. Nagaraju and U.H. Babu (2012), [7] in their paper, have replaced the conventional materials of the chassis frame with Carbon Epoxy and E-Glass Epoxy composites. Structural and Modal Analyses are conducted by varying the layers and the reinforcement angles in the layers. Results have shown that the Carbon and E-Glass Epoxy have generated low stress values than the conventional steel material when subjected to vertical loads. The weight is reduced four times than the steel frame. It is also observed that using many layers of same thickness has given better strength than a single layer.

M.R. Chandra et al. (2012), [8] have described the design and analysis of a heavy vehicle chassis. The dimensions of a TATA 2515EX vehicle is taken for modeling and analysis with three different materials, Carbon/Epoxy, E-Glass/Epoxy and S-Glass/Epoxy, subjected to the same loading conditions as that of a Steel chassis. With similar design specifications, the composite frame has shown reduced stress and deflection values than the conventional steel, also reducing the weight of the chassis frame.

\section{PROBLEM SPECIFICATION}

The objective of the present work is to design and analyse the front end transverse cross member made from steel and also made from composite material like Carbon Fiber Reinforced Polymer (CFRP). The chassis frame is modelled in CREO and is imported to ANSYS 14.5 for analysis under normal loading conditions. The deflections and stress results of convetional steel chassis and CFRP is compared after analysis in order to choose the better material. 


\section{MOdelLing AND STATIC ANALysis OF Chassis FRAME}

\section{A. Modelling}

The chassis frame is model is created using CREO modelling software.

\section{B. Analysis}

The model created in CREO is imported to ANSYS. During the analysis, the following boundary conditions, element types and material properties are considered.

i. Elements Considered: Shell63 and Shell99 elements are considered for analysis. The Shell63 is a four noded element having six degree of freedom at each node. Whereas, the Shell99 is used in layered configuration and it is a eight noded element having six degrees of freedom at each node.

ii. Material Properties: The material properties considered for analysis are listed in table 3.1

iii. Boundary Conditions: Since we consider the front end transverse cross bar only, the ends of the cross bar are applied as boundary conditions.

iv. Loading Condition: The front end transverse cross bar is mounted with radiator fittings, engine bed and other minor accessories. Thus, the average load applied to the bar is taken as $20 \mathrm{kN}$.

\section{DIMENSIONS OF CHASSIS FRAME}

\section{Vehicle Model: TATA407}

The longitudinal cross members, diagonal cross members and transverse cross members are made from ' $\mathrm{C}$ ' channels of dimension $125 \mathrm{~mm}$ x $65 \mathrm{~mm}$ x $8 \mathrm{~mm}$

The front-end transverse cross bar is made from box section of dimensions $65 \mathrm{~mm} \times 125 \mathrm{~mm}$ x $8 \mathrm{~mm}$

Front Overhang $=710 \mathrm{~mm}$

Rear Overhang $=840 \mathrm{~mm}$

Wheel Base $=3200 \mathrm{~mm}$

Front Wheel Track $=710 \mathrm{~mm}$

Rear Wheel Track $=1016 \mathrm{~mm}$

Angle of divergence at the

front-end near the cross bar $=20^{\circ}$

Table 1: Mechanical Properties of Materials

\begin{tabular}{|l|l|l|}
\hline $\begin{array}{l}\text { Material } \\
\text { Properties }\end{array}$ & STEEL & CFRP \\
\hline $\begin{array}{l}\text { Young's } \\
\text { Modulus } \\
\left(\mathrm{N} / \mathrm{mm}^{2}\right)\end{array}$ & $2.1 \times 10^{5}$ & $17.5 \times 10^{3}$ \\
\hline $\begin{array}{l}\text { Density } \\
\left(\mathrm{kg} / \mathrm{mm}^{3}\right)\end{array}$ & 7850 & 1500 \\
\hline Poisson's Ratio & 0.3 & 0.35 \\
\hline
\end{tabular}

\section{RESULTS AND DisCUSSIONS}

The deformation and von-mises stress distribution of both conventional steel and Carbon Fiber Reinforced Polymer is determined through analysis. The deformation of the frame is transferred from the front most end throughout the frame. The stress is distributed evenly on both the longitudinal cross bars.

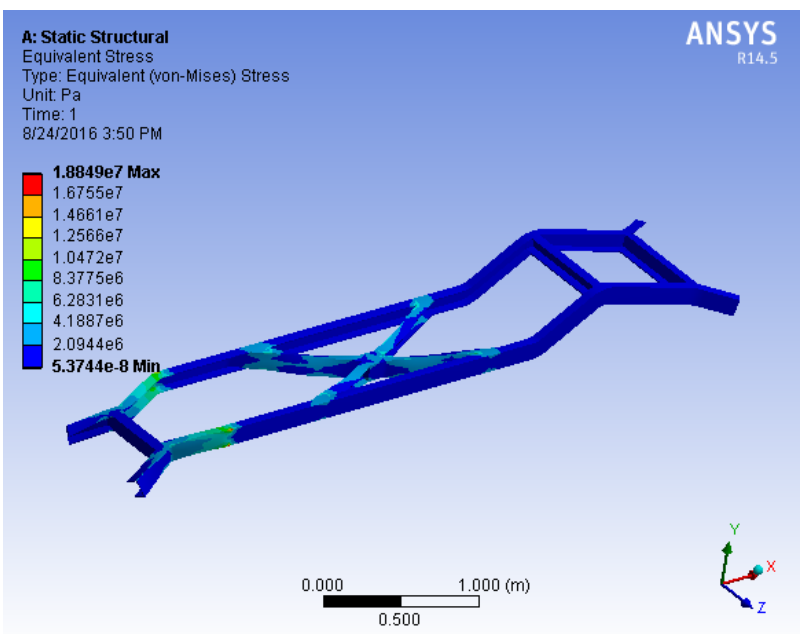

Figure 1: Von-mises Stress Distribution in CFRP

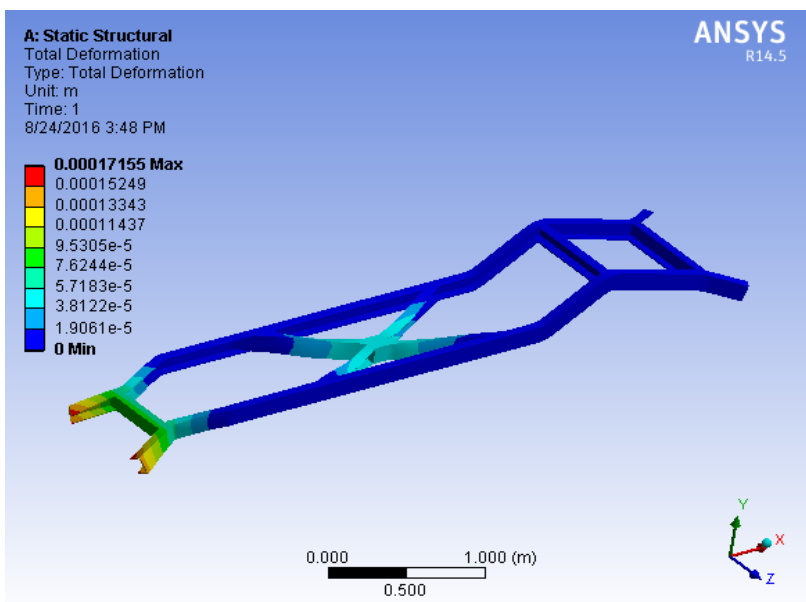

Figure 2: Deformation in CFRP

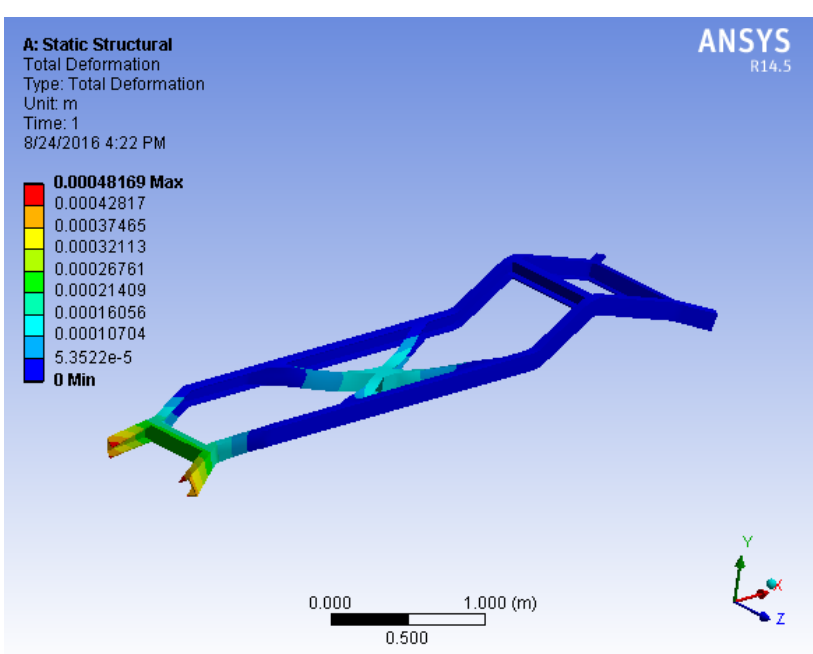

Figure 3: Deformation in Steel 


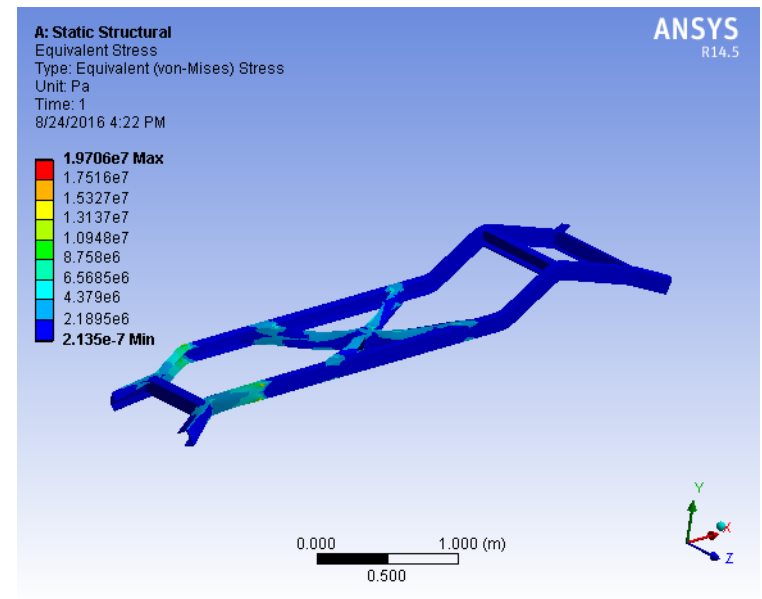

Figure 4: Von-mises Stress Distribution in Steel

The magnitude of deflection and stress of conventional Steel and Carbon Fiber Reinforced Polymer are tabulated in Table II. From the results it is clear that the CFRP is better than the steel.

Table 2: Deflection and Von-mises Stress Distribution in Static Analysis

\begin{tabular}{|l|l|l|}
\hline & STEEL & CFRP \\
\hline Deflection $(\mathrm{mm})$ & $48.169 \times 10^{-5}$ & $17.155 \times 10^{-5}$ \\
\hline Stress $\left(\mathrm{N} / \mathrm{mm}^{2}\right)$ & $1.9706 \times 10^{7}$ & $1.8849 \times 10^{7}$ \\
\hline
\end{tabular}

\section{CONCLUSION}

The carbon fibers are more suitable for ,most of the automotive applications. The replacement of the front-end cross bar only with CFRP has given better results than steel.

Thus when we replace the convetional steel with CFRP:

- the deflection of the cross bar is reduced by $64.38 \%$

- the stress developed in the bar is reduced by $4.34 \%$

\section{REFERENCES}

[1] Chintada Vinnod Babu, Chiranjeeva Rao Seela and Vykunta Rao Matta, "Structural Analysis of Eicher 11.10 Chassis Frame", International Journal of EngineeeringTrends and Technology (IJETT), Vol. 22, No. 7, Pp. 315-318, 2015.

[2] Kshitija A. Bhat and Harish V. Katore, "The Failure Analysis of Tractor Trolley Chassis An Approach using Finite Element Method- A Review", IOSR Journal of Mechanical and Civil Engineering (IOSR-JMCE), Pp. 24-27, 2014.

[3] Hemant B.Patil, Sharad D.Kachave and Eknath R.Deore, "Stress Analysis of Automotive Chassis with Various Thicknesses", IOSR Journal of Mechanical and Civil Engineering (IOSR-JMCE), Vol. 6, No. 1, Pp. 44-49, 2013.

[4] Tushar M. Patel, Dr.M.G. Bhatt and Harshad K. Patel, "Analysis and validation of Eicher 11.10 chassis frame using Ansys", International Journal of Emerging Trends \& Technology in Computer Science (IJETTCS), Vol. 2, No. 2, Pp. 85-88, 2013.

[5] V. Patel Vijaykumar and R.I. Patel " "Structural Analysis of Automotive Chassis Frame and Design Modification for Weight Reduction", International Journal of Engineering Research\&Technology (IJERT), Vol. 1, No. 3, Pp. 1-6, 2012.

[6] Mohd Azizi Muhammad Nora, Helmi Rashida, Wan Mohd Faizul Wan Mahyuddin, "Stress Analysis of a Low Loader Chassis", Elsevier Ltd. Sci Verse Science Direct Procedia Engineering, Vol. 41, Pp. 995- 1001, 2012.

[7] J.S.Nagaraju and U.H. Babu, "Design and structural analysis of heavy vehicle chasis frame made of composite material by varying reinforcement angles of layers", International Journal of Advanced Engineering Research and Studies, Vol. 1, No. 2, Pp. 70-75, 2012.

[8] M.R. Chandra, S. Sreenivasulu and S.A. Hussain, "Modeling and Structural analysis of heavy vehicle chassis made of polymeric composite material by three different cross sections", International Journal of Modern Engineering Research (IJMER), Vol. 2, No. 4, Pp. 2594-2600, 2012.

[9] R.A. Rahman, M.N. Tamin and O. Kurdi, "Stress analysis of heavy duty truck chassis as a preliminary data for its fatigue life prediction using FEM”, Jurnal Mekanikal, Vol. 26, Pp. 76 - 85, 2008. 